\title{
Soil-Transmitted Helminths Infection among Primary School Students: Which Policy Should be Emphasized?
}

\author{
Bumi Zulheri Herman ${ }^{1,2}$, Ranisa Handayani Ramlan ${ }^{3}$, Ferawati Rahmat ${ }^{4}$ \\ ${ }^{1}$ Department of Public Health and Community Medicine, Faculty of Medicine Hasanuddin University, Indonesia \\ ${ }^{2}$ College of Public Health Sciences, Chulalongkorn University, Thailand \\ ${ }^{3}$ Department of Clinical Pathology, Faculty of Medicine Hasanuddin University, Indonesia \\ ${ }^{4}$ Clinical Laboratorium, Local Office of Public Health Balikpapan, Indonesia
}

\begin{tabular}{|c|c|}
\hline Article Info & ABSTRACT \\
\hline Article history: & Soil Transmitted Helminths is a neglected disease and remain untouched in \\
\hline Received Apr 25, 2018 & $\begin{array}{l}\text { Balikpapan despite of its deteriorating effects on child health. A cross- } \\
\text { sectional study to reveal the actual infection among school-age children in }\end{array}$ \\
\hline Revised Jun 6, 2018 & Balikpapan was conducted from January-March 2016 involved 101 students \\
\hline Accepted Jun 6, 2018 & $\begin{array}{l}\text { from } 10 \text { schools. All subjects and parents were interviewed using validated } \\
\text { questionnaire followed by stool examination. All data underwent univariate }\end{array}$ \\
\hline Keyword: & $\begin{array}{l}\text { and bivariate test using fisher exact's test, ANOVA and logistic regression } \\
\text { test }(95 \% \mathrm{CI}) \text {. Rate of positive infection was } 62.4 \% \text {. Associated risk factors }\end{array}$ \\
\hline Child health & were, routine hand wash $(\mathrm{p}=0.004 \mathrm{OR}=0.050)$, taking oral prophylaxis \\
\hline Health policy & "Young Doctor Program" or other health promotion program $(p=0.014$ OR \\
\hline Health promotion & $0.324)$ and the type of toilet at home $(\mathrm{p}=0.048)$. Knowledge about worm \\
\hline Helminthiasis & infection $(\mathrm{p}=0.659)$, history of previous worm infection $(\mathrm{p}=0.768)$ and access \\
\hline Primary care & $\begin{array}{l}\text { to clean water at home ( } \mathrm{p}=0.361) \text { were insignificantly associated with } \\
\text { infection rate. Community service (such as "The Clean, Green And Healthy" } \\
\text { program) ( } \mathrm{p}=0.037 \text { OR 0.395) and Community Health Care ( } \mathrm{p}=0.000 \text { OR } \\
0.155 \text { ) were associated with lower risk of infection. Regression test shows } \\
\text { that community health care and oral prophylaxis were the most influencing } \\
\text { factor and these factors should be considered as the main focus of } \\
\text { intervention. }\end{array}$ \\
\hline
\end{tabular}

Copyright @ 2018 Institute of Advanced Engineering and Science. All rights reserved.

\section{Corresponding Author:}

Bumi Zulheri Herman, College of Public Health Science, Chulalongkorn University, Institute Building $3\left(10^{\text {th }}-11^{\text {th }}\right.$ floor $)$, Chulalongkorn soi 62 , Phyathai Rd., Bangkok 10330, Thailand.

Email: bumizulheriherman@gmail.com

\section{INTRODUCTION}

Balikpapan is a growing city situated in East Kalimantan Province. Its vision as "Child Friendly City" encourage the government to create policies to accomodate children to grown up in the best environment, from best education, to best health coverage and service. In school-age, the Public Health Office are focusing on how to increase the ability of students to achieve highest learning retention and maintain their health status.

The health policy focus in Balikpapan is how to eradicate diseases which may affect the health status in school-age. Soil Transmitted Helminth (STH) infection is a neglected disease which may affect the growth and development of children especially in their school-age. In Indonesia, the rate of STH infection reach approximately $22.12 \%$ in 2012 and based on 2014 WHO data, only $10.98 \%$ of school-age children were treated with oral prophylaxis [1]. Most of cases cannot be distinguished to other cases without 
laboratory examination as STH can appear as gastrointestinal disturbances, skin manifestation, mild malnutrition, unexplained anemia, or some mild signs and symptoms including less attention to study, weakness, et cetera. The rate of STH infection in Balikpapan is not clearly recorded, but in a glance, some cases of STH were found including intestinal and mucocutaneus manifestation in Primary Health Care (PHC).

There were some factors that associated with STH infection, the socio-demography factors (knowledge and health behavior) and WASH factors (Water, Sanitation and Hygiene) as mentioned by the study of Freeman [2]. There are some programs and policies related to WASH applied in the city including the health promotion such as Young Doctor Program, community healthcare, and the "Clean Green and Healthy program". The main objectives of the study are to reveal an actual rate of STH infection among primary school children and its associated factors, to analyze present policies and program related to WASH factors and how effective these policies can reduce the worm infection. A further recommendation will be made to create a specific and effective policy in eradicating worm infection based on the result of this study.

\section{RESEARCH METHOD}

This study was performed in cross-sectional method from January to March 2016 involving 101 students age 6-13 years old in 10 schools represents 6 districts in Balikpapan. An informed consent was given to parents and students including the purposes of study, method of stool examination, results and further plan including oral prophlyaxis for negative cases and specific treatment for positive cases using albendazole. A questionnaire (13 validated items) was composed to assess the factors which underwent reliability (Cronbach Alpha Score 0.801) and validity test (using Product Moment Pearson). This questionnaire were asked to all subjects and their guardian followed by stool examination. Variables to be measured by the questionnaire are, routine hand-wash, knowledge of worm infection, use of footwear, attending health promotion/ young doctor program, previous history of worm infection, access to toilet, source of clean water, oral prophylaxis, community health care by PHC, and Social Working/CGH (Clean Green and Healthy). For measuring the knowledge about worm infection, the students were asked 3 questions (included in validated questionnaire) to measure their knowledge, the sign and symptoms of worm infection (mention 4 answers), how worm infect the human (at least 3 answers include: nail, foot, animal flesh, feces) and how to prevent the STH (at least 3 answers, hand wash, nail clipping, use footwear, take anti-helminth drug). Students were classified as having sufficient knowledge if they can answer 5 from 10 expected answers.

A total of 101 samples were collected and analyzed at the same day when the subjects were interviewed. Samples were analyzed in Manggar Baru PHC laboratorium (standardized by ISO 15189:2003) using Kato Katz method [3-4]. Identification of helminths morphology such as eggs, larvae and adult worm was performed and cross-checked by laboratory staff. Positive findings will be noted as positive and vice versa.

A closed interview to 10 teachers from 10 schools, 27 Primary Health Care Center representatives and 15 sub-district office were conducted to analyze and confirm some answers and health behaviour of the respondents and also to obtain some information about the role of each institution in STH eradication (such as the Young Doctor Program, Annual Oral Prophylaxis, community health care by PHC such as stop Open Defecation Free Campaign, sanitation intervention, and the "Clean Green and Healthy Program" held by the District office to promote sanitation, green environment, and no smoking area)

All parameters were analyze descriptively and bivariate using Chi Square/Fisher Exact Test (if Chi Square is unable), and Logistic Regression Test to reveal the most influencing factor of STH infection using statistic software SPSS 16.0 version. Odd Ratio also analyzed, with 95\% Confidence Interval (p value $<0.05$ considered as significant).

\section{RESULTS AND ANALYSIS}

A total 101 students were involved in this study and their age varies from 6-13 years old (mean age 10 years 3 months old SD \pm 1.28756$)$. Most of students come from District Central (29.7\%) followed by District West (21.8\%) District East (18.8\%) Distric South (17.8\%) and District North (11.9\%), as shown in Table 1. Number of infected student is 63 (62.4\%) with most common infection is Ascaris sp, followed by Trichuris sp and Ancylostoma Sp. Mixed infection were also found. The authors do not identifed the eggs per gram faeces as it will not significantly change the doses of oral prophylaxis. Table 2 (a) and (b) shows about subject's demography characteristic. 


\begin{tabular}{ccc}
\multicolumn{3}{c}{ Table 1. Infection Type } \\
\hline Infection & Frequency & Percent/infected \\
\hline Ascaris $s p$ & 34 & 53.97 \\
Trichuris $s p$ & 17 & 26.98 \\
Ancylostoma $s p$ & 9 & 14.29 \\
Mixed Infection & 3 & 4.76 \\
No Infection & 38 & - \\
\hline
\end{tabular}

Table 2 (a). Subjects Demography Characteristic

\begin{tabular}{cll}
\hline Element & \multicolumn{2}{c}{ Number } \\
\hline Age (year) & Mean & 10.2673 \\
& Minimum & 6 \\
& Maximum & 13 \\
Sex & Male & 59 \\
& Female & 52 \\
\hline
\end{tabular}

Table 2 (b). Subjects Demography Characteristic

\begin{tabular}{clcc}
\hline Element & & \multicolumn{2}{c}{ Number } \\
& & Infected & Not Infected \\
\hline \multirow{6}{*}{ Area } & West & 18 & 4 \\
& East & 19 & 0 \\
& South & 6 & 12 \\
& North & 6 & 6 \\
& Central & 14 & 16 \\
\hline
\end{tabular}

\subsection{Knowledge, Attitude and Practice}

Only 78 students $(77.23 \%)$ wash their hand routinely with soap. Interestingly, 41 from 78 students who perform hand wash routinely still get infected. Routine hand wash shows protective effect to worm infection ( $\mathrm{p}=0.004 \mathrm{OR}=0.05095 \%$ CI 0.006-0.392).

About $20(31.74 \%)$ infected students did not wear foot cover/flipfloes while playing on the ground. Students that wearing footwear tend to have lower risk of infection $(\mathrm{p}=0.009 \mathrm{OR}=2.529$ 95\% CI 1.2565.095). Previous history of worm infection within the last 1 year based on clinical signs, and symptomps or obvious infection (eg worm in stool etc) was insignificantly associated with infection $(\mathrm{p}=0.768)$. Fourty three students with positive infection never experienced worm infection before. Around 63 from 101 students had pyrantel pamoate as oral prophylaxis. Previous oral prophylaxis shows protective effect $(\mathrm{p}=0.001 \mathrm{OR}=0.182$ $95 \%$ CI $0.067-0.495$ ). About 56 of them only take once in their lifetime and the rest are taking twice anually as recommended by the national campaign. Unfortunately 31 from these 63 students still get infected.

Their knowledge about worm infection are insignificantly correlated with infection $(\mathrm{p}=0.659)$ as there are 26 students with sufficient knowledge about worm infection still get infected. Health promotion program about worm infection is also analyzed. Every student were asked about wether they ever attending health promotion program such as hand wash campaign or worm campaign or attend the "Young Doctor Program". The odd ratio of attending health promotion program is ( $\mathrm{p}=0.016 \mathrm{OR}=0.32495 \%$ CI 0.129-0.814). About 52 infected students never join or attend health promotion program.

At least 10 teacher froms 10 schools of students involved in this study were also interviewed. Only 1 from 10 schools at this study held a "Worm Infection Campaign" within the last 6 months ago. All schools admitted that there is no regulation or specific integrated program to diminish worm infection in students. The "Young Doctor Program" is training held anually by PHC to promote health behaviour including routine hand wash and wearing footwear and delegate certain students as Young Doctor and become the health pioneer for their friends. But the content of training held in school is not specificaly include the worm infection content.

\subsection{Sanitation Aspects and Intervention.}

Investigation for appropriate sanitation was also performed. There are 13 students who dont have appropriate toilet at home (goose-neck type connected through septic tank) consist of pit/hole latrine and 7 of them dont have. The type of toilet was significantly associated with worm infection ( $\mathrm{p}=0.048)$ but Odd Ratio cannot be computed. The source of clean water at home such as well, treated water, or other resource is not corelated with the incidence of worm infection $(\mathrm{p}=0.361)$.

The role of primary health care is also identified in community. Parents were asked is there any effort of the Primary Health Care to held a community health care, such as sanitary inspection, health 
promotion or health campaign based on "10 Health Behaviour" or known as "Perilaku Hidup Bersih dan Sehat" at their home. A total of 51 respondents said that the Primary Health Care at their district already made such program and they were involved ( $\mathrm{p}=0.000$ OR $0.15595 \%$ CI $0.062-0.387$ )

As total 27 Primary Health Care was not conducting a specific prevention program of worm infection as expected. During the last 3 years, there was no integrated program such as screening, and oral prophylaxis. The open defection free campaign was planned but did not conducted as expected. Number of no-ODF sub-district was never declared. The PHC were focus on sanitary inspection and health promotion through counselling. All positive cases found in outpatient care were treated selectively with pyrantel pamoate and albendazole. Incidence rate of worm infection is approximately less than $1 \%$ per population as confirmed in Local PHC system. Cutaneous manifestation was not recorded specificly.

Information about the role of subdistrict Office was obtained from questionnaire and interview. Only 126 from 1360 cluster is applying "Clean Green and Healthy (CGH)" program and facilitated by the subdistrict office. These programs consist of Implementation of "Perilaku Hidup Bersih dan Sehat" or 10 "Health Behaviour", zero smoke/tobacco area and integrated environment program. Social working to clean the environment is one of the elements in the "Clean Green and Healthy" program. The subjects who live in the sub-district/cluster that conducted the $\mathrm{CGH}$ program tend to have lower risk of worm infection $(\mathrm{p}=0.037$ OR $0.39595 \%$ CI $0.167-0.930)$. Nonetheless this program was independently held without coordination from PHC.

Logistic Regression Test was conducted to reveal the most influencing factor. Community health care such as sanitary inspection, and health promotion held by PHC $(\beta=-2.028 \mathrm{p}=0,001)$ and taking oral prophylaxis $(\beta=-1.275 \mathrm{p}=0.001)$ are the most influencing factor. The estimation of infection is $\mathrm{Y}=9.321$ 1.275 (Oral Prophylaxis)-2.028(Community Health Care) with yes as higher dichotomy. This can predict for up to $80.2 \%$ possibility of infection (adjusted R2 0.802). Variable analysis is shown in Table 3.

Table 3. Variable Analysis

\begin{tabular}{|c|c|c|c|c|c|c|}
\hline \multicolumn{2}{|l|}{ Variables } & Infected & Not & OR & $95 \%$ Exp & P Value \\
\hline \multirow{3}{*}{ Routine Handwash } & Yes & 41 & 37 & 0.050 & $0.006-0.392$ & $\mathrm{p}=0.004$ \\
\hline & No & 22 & 1 & & & \\
\hline & Yes & 26 & 14 & 1.205 & $0.526-2.758$ & $\mathrm{p}=0.659$ \\
\hline \multirow[t]{2}{*}{ Sufficient Knowledge of Worm Infection } & No & 37 & 24 & & & \\
\hline & Yes & 43 & 34 & 2.529 & $1.256-5.095$ & $\mathrm{p}=0.009$ \\
\hline \multirow[t]{2}{*}{ Wearing footwear while playing on the ground } & No & 20 & 40 & & & \\
\hline & Yes & 11 & 15 & 0.324 & $0.129-0.814$ & $\mathrm{p}=0.016$ \\
\hline Attending Health Promotion/ Young Doctor Program & No & 52 & 23 & & & \\
\hline \multirow[t]{2}{*}{ Previous History of worm infection } & $\begin{array}{l}\text { Yes } \\
\text { No }\end{array}$ & $\begin{array}{l}20 \\
43\end{array}$ & $\begin{array}{l}11 \\
27\end{array}$ & 1.142 & $0.474-2.750$ & $\mathrm{p}=0.768$ \\
\hline & $\begin{array}{l}\text { Yes } \\
\text { No }\end{array}$ & $\begin{array}{l}31 \\
32\end{array}$ & $\begin{array}{c}32 \\
6\end{array}$ & 0.182 & $0.067-0.495$ & $\mathrm{p}=0.001$ \\
\hline Taking Oral Prophylaxis & Goose Neck & 51 & 37 & & & \\
\hline \multirow[t]{2}{*}{ Has toilet with appropriate sanitation } & Non Goose Neck & 5 & 1 & NA & NA & $\mathrm{p}=0.048$ \\
\hline & $\begin{array}{l}\text { Dont Have } \\
\text { Treated Water }\end{array}$ & $\begin{array}{c}7 \\
45\end{array}$ & $\begin{array}{c}0 \\
31\end{array}$ & & & \\
\hline \multirow[t]{3}{*}{ Source of Clean Water } & Well & 16 & 7 & NA & NA & $\mathrm{p}=0.361$ \\
\hline & Dont have & 2 & 0 & & & \\
\hline & Yes & 21 & 29 & 0.155 & $0.062-0.387$ & $\mathrm{p}=0.000$ \\
\hline Community Health Care by PHC & No & 42 & 9 & & & \\
\hline \multirow[t]{2}{*}{ Social Working / CGH } & Yes & 31 & 27 & 0.395 & $0.167-0.930$ & $\mathrm{p}=0.037$ \\
\hline & No & 32 & 11 & & & \\
\hline
\end{tabular}

\section{DISCUSSION}

This study was focused on three sectors, Schools and its students, Primary Health Care and the Subdistrict Office. From 101 students around 29.7\% live in District Central which is well known as populous middle-income district. South District is the capital district of Balikpapan. East and West are commonly known as sub-urban district where most of the population are not the native people/transmigrant. Most of them work as fisherman, and classified in low-income family. They live near the river bank in a semipermanent house with inappropriate sanitation. Perhaps, this might contribute to higher number of positive infection at those districts. Furthermore, the results of this study supported the assumption that own a proper toilet have significant association with worm infection $(\mathrm{p}=0.048)$ Similar finding were also revealed by Ashenafi in 2013, a toilet with an open system is associated with worm infection (OR $3.618 \mathrm{p}<0.05$ 1.304-10.04) [5]. The point showed by Ziegelbauer in 2012 said that a combination of sanitation availability and use, were showing protective effect with odd ratio 0.51 (95\% CI 0.44-0.61) for the three soil-transmitted 
helminths combined, 0.54 (95\% CI 0.43-0.69) for A. lumbricoides, 0.58 (95\% CI 0.45-0.75) for T. trichiura, and $0.60(95 \%$ CI $0.48-0.75)$ for hookworm [6]. North District is the less populated district as only few housing complex available and most of the landscape are hills and forest. Most of people in North District work as farmer and not wearing footwear contribute to worm infection as reveled in this study, footwear give protective effect to worm infection ( $\mathrm{p}=0.015$ OR 2.529 95\% CI 1.256-5.095). Study conducted by Strunz in 2014 also have the similar finding that wearing shoes was associated with reduced odds of hookworm infection (OR 0.29, 95\% CI 0.18-0.47) and infection with any STH (OR 0.30, 95\% CI 0.11-0.83) [7]. Tilahun Alelign in 2015 also revelaed the same results that the hookworm infection may occur 2.42 times higher [8]. Another different result as mentioned by Kaliappan et al (2013) that poor usage of footwear was not associated with increased risk of STH infection [9].

Sex was not reviewed for significant factors as mentioned by Uneke in 2006 and Kaliappan (2013) that there is no significant difference of STH infection between male and female [9-10]. The finding of Tilahun Alelign is also similar with this study [8]. Routine handwash is defined as a handwash procedure performed using hand soap in six steps as recommend by WHO. In this study there were only 78 students (77.23\%) wash their hand routinely with soap. In this study, routine hand wash shows protective effect to worm infection ( $\mathrm{p}=0.004$ OR $0.05095 \%$ CI $0.006-0.392$ ). A study by Strunz obtained the similar results especially, when handwash is performed after defecating and before eating [7]. Routine hand wash training is also included in "Young Doctor" training held by PHC but the author still find 41 from 78 students who perform hand wash routinely still get infected by worm. This could possibly happen due to inappropriate routine hand wash. Perhaps students are performing hand wash in incorrect steps, duration or even dont use handsoap routinely. This may lead to worm infection as incorrect routine hand wash will not make hand and nails clean.

In questionnaire, students and parents were asked whether their children have some obvious signs and symptomps of worm infection in the past or they ever experienced visible worm (such as intestine worm comes out from rectum or any mucocutaneus manifestation/ cutaneous larva migrans). Thirty one students had previous worm infection and 20 of them have worm infection in this study. A study of STH reinfection is performed by Jia TW in 2012 and it shows that even after treatment, the risk of reinfection from 26-94\% 3, 6 and 12 months afterward [11]. Reinfection is likely occurs in children if they cannot implement all aspects of health behaviour for example nail clipping. In the study of Mahmud in 2015 shows that reinfection of STH after 6 months for the group "handwash with soap" is $14.28 \%$ and combination of handwash and nail clipping is $13.82 \%$ eventhought is not significant $(\mathrm{p}=0.069)$ [12]. Our study shows there is no corelation between previous worm infection and the worm infection at this time $(\mathrm{p}=0.768)$. This might be the effect of multiple factors such as oral prophylaxis, knowledge and sanitation.

Only 40 students have adequate knowledge about worm infection. The author found that adequate prior knowledge is not siginificantly corelated with worm infection $(\mathrm{p}=0.659)$ Study by Sitti Chadijah in 2014 also support this finding $(\mathrm{p}=0.466)$ [13]. The cause of this finding perhaps is the implementation of their knowledge in daily life. At schools, students can perform hand wash but not at home or any other possibilities which cannot enforce them to apply their knowledge, such as no trustworthy role model (parents, family) or lack of facilities such as sink to do handwash or lack of obedient itself.

As mentioned above, the "Young Doctor Program" is a training held anually by PHC to promote health behaviour in schools. Teacher appoints certain number of students as Young Doctor and become the health pioneer/role model for their friends after pass the training. Beside that, some specific health campaign to promote "10 Perilaku Hidup Bersih dan Sehat" ("10 Health behaviour") also held by PHC anually such as hand wash campaign. But lately the specific worm infection content is not included or deeply trained in this program. Only one schools held a spesific worm eradication campaign in District North. Our study shows that every students that ever join such activities tend to have lower risk of infection ( $\mathrm{p}=0.016$ OR $0.32495 \%$ CI 0.129-0.814). Several studies are showing some similar results that health promotion can reduce worm infection such as research performed by Gyorkos in 2013 shows that health promotion intervention is asscoiated with worm infection and tend to lower the risk of infection especially for Ascariasis up to 58\% [14]. In our study we can assume that the health promotion performed by health staff can guarantee the correct information about how to apply the "Health Behaviour" in desirable way. The author examine further that community health care performed by the PHC staffs including sanitary inspection, direct public health intervention and health promotion directly to people is statistically significant $(\mathrm{p}=0.000)$ Different results revealed by Thomas Clasen that the intervention consisted of latrine promotion and construction) are not significantly reduce the egg-count prevalence of STH in India [15]. But Still, the researchers recommend the PHC sanitarian to focus on promoting good sanitation toilet and reduce the open defecation behavior as clearly stated in a study of Ashenafi that open defecation will contribute to worm infection ${ }^{5}$. This problem is obviously seen in District West and East. An urge action should be done as type of toilet is corelated with worm infection eventhought the odd ratio in this study cannot be calculated $(\mathrm{p}=0.048)$. The source of clean 
water at home is not associated with worm infection $(\mathrm{p}=0.361)$. Different results revealed by Strunz and Worell that treated water may have protective effect on STH infection [7], [16]. Most of students have treated water supplied from local company. Few of them still use well and the author still found some subject who dont have source of clean water. They might get from their neighbour or collect water from rain.

Oral prophylaxis taken by students was identified and there were 63 from 101 student did. They take once in their lifetime and some other was routinely taken twice annually as mentioned in results. All parents choose Pyrantel Pamoate which is extensively known, rather than albendazole. The efficacy of pyrantel pamoate compare to Albendazole is $32 \%$ versus $72 \%$ respectively for hookworm infection [17]. Speich et al 2012 expressed that albendazole and mebendazole, as well as pyrantel pamoate and levamisole are recommended drugs against infections with soil-transmitted helminths [18]. Hence, the author still be able to find 31 from 63 students with previous oral prophylaxis get infected at this time. Deworming effort using oral prophylaxis based on a study of Taylor in 2012 shows that a single dose of deworming drugs probably increased weight and haemoglobin (low quality evidence), but less evidence of effect on cognitive functioning [19]. Our study reveals that oral prophylaxis shows still have promising protective effect $(\mathrm{p}=0.001$ OR $0.18295 \%$ CI $0.067-0.495)$.

As mentioned above that there was no specific prevention program of worm infection, screening, and oral prophylaxis conducted by PHC. Selective treatment was done with pyrantel pamoate or albendazole. According to the national STH guidelines there should be a specific program and person in charge for area with higher infection (>50\%) and this guidelines is also strengthened by the Ministry Of Health Regulation number 75 year 2014 appendix section clearly stated that in a city, the STH eradication program should be established by the primary health care [20].

The authors investigate the role of government institution (Sub-district Office) in a questionnaire. A cluster/subdistrict is defined as an area of 50 families live subsequently in certain. As 2016, 126 from 1360 cluster are applying "Clean Green and Healthy (CGH)". The CGH program tend to have lower risk of worm infection ( $\mathrm{p}=0.037$ OR $0.39595 \%$ CI $0.167-0.930$ ), especially the social working moment to clean the environment. The author notice that this program is not integrated with PHC policy. Mostly the CGH program is an innate effort from people itself. If the CGH is integrated with Community Health Care, there will be strong possibilities to eradicate worm infection.

The logistic regression test shows that community health care and oral prophylaxis are the most influencing factor. Therefore, recommendation should be focused on these factors. A study of Mascarina Serra in 2011 and Jia TW in 2012 revealed that an STH policies should at least consists of regular anthelminthic treatment, health education, sanitation and personal hygiene and other means of prevention. Those policies are linier with our results [11], [21].

\section{CONCLUSION AND RECOMMENDATION}

This study still has some lack and need to be improved especially for further study. The severity of infection can be identified using egg per grams of stool eventhought it will not affect the type of medication. Clinical manifestation can be identified to predict the severity of infection and attempting appropriate treatment. A larger sample is expected for accuracy.

Based on this study results, the author recommend an integrated program to diminish STH. The first is creating specific program and appointing person incharge to be responsible for the program in Primary Health Care. Secondly, the person in charge should build a program consist of health promotion of worm infection especially in school age. The "Young Doctor" program should be revised to add worm infection content, hand wash demonstration and the use of footwear. The PHC should make an integrative community health care and CGH program. The person in charge will identify the risk factor in population and become the role model in promoting health behaviour. A suggestion from distric South said, that there should be "Hand Hygiene" moment in CGH program, so when people attending meeting, gathering, should begin by a brief demonstration how to perform routine hand wash as trained by the PHC staffs. In level of early detection and prompt treatment, the annual screening for students in new enrolment should include the stool examination if possible and followed by giving prophylaxis dose with Albendazole. An integrated Community Health Care and CGH program should be extended to entire city. The annual rate of worm infection can be used as an evaluation of success program. And the author cannot deny that a willingness and collective effort from individual/sector in investing good sanitation play important role.

\section{ACKNOWLEDGEMENTS}

The author would like to appreciate for supports and permission to Public Health Office Balikpapan City, The Primary Health Care, Sub-district office, Schools, Students and Parents that involved in this study. 
Highest appreciation is given to Primary Health Care Manggar Baru Balikpapan for becoming the centre for our study. These studies are funded solely by the authors and declare no conflict of interest.

\section{REFERENCES}

[1] World Health Organization. Soil-transmitted helminthiasis Indonesia. http://www.who.int/neglected_diseases/preventive_chemotherapy/sth/db/?units=minimal@ion=all\&country=idn\&c ountries=idn\&year=2014 (accessed 27 June 2016).

[2] Freeman MC, Chard AN, Nikolay B, Garn JV, Okoyo C, Kihara J et al. "Associations between school and household-level water, sanitation and hygiene conditions and soil-transmitted helminth infection among Kenyan school children", Journal Of Parasites And Vectors 8,412, 2012.

[3] Tarafder M, Carabin H, Joseph L, Balolong E, Olveda R, McGarvey S., "Estimating the sensitivity and specificity of Kato-Katz stool examination technique for detection of hookworms, Ascaris lumbricoides and Trichuris trichiura infections in humans in the absence of a "gold standard"”, International Journal For Parasitology (40):399-404, 2010.

[4] Idris MA, Al-Jabri AM., "Usefulness of Kato-Katz and trichrome staining as diagnostic methods for parasitic infections in clinical laboratories" Journal for scientific research Medical sciences/Sultan Qaboos University, 3(2):65-68, 2002.

[5] Ashenafi A, Seid M., "Assessment of the prevalence of intestinal parasitosis and associated risk factors among primary school children in Chencha town", Southern Ethiopia. BMC Public (14):166, 2014.

[6] Ziegelbauer K, Speich B, Mäusezahl D, Bos R, Keiser J, Utzinger J., "Effect of sanitation on soil-transmitted helminth infection: systematic review and meta-analysis", Hales S, ed. PLoS Medicine, 9(1), 2012.

[7] Strunz EC, Addiss DG, Stocks ME, Ogden S, Utzinger J, Freeman MC., "Water, sanitation, hygiene, and soiltransmitted helminth Infection: A systematic review and meta-analysis", PLoS Med (11);3, 2014.

[8] Alelign T, Degarege A, Erko B., "Soil-transmitted helminth infections and associated risk factors among school children in Durbete Town, Northwestern Ethiopia”, Journal of Parasitology Research, 5, 2015.

[9] Kaliappan SP, George S, Francis MR, et al., "Prevalence and clustering of soil-transmitted helminth infections in a tribal area in southern India", Tropical medicine \& international health : TM \& IH, 18(12):1452-1462, 2013.

[10] Uneke C, Eze K, Oyibo P, Azu N, Ali E, "Soil-transmitted helminth infection in school children in south-eastern nigeria: The public health implication", The Internet Journal of Third World Medicine, (4);1, 2006.

[11] Jia T-W., Melville S., Utzinger J., King CH, Zhou X-N., "Soil-transmitted helminth reinfection after drug treatment: A systematic review and meta-analysis”, Cooper PJ, ed. PLoS Neglected Tropical Diseases, 6(5):e1621, 2012.

[12] Mahmud MA, Spigt M, Bezabih AM, Pavon IL, Dinant G-J, Velasco RB., "Efficacy of handwashing with soap and nail clipping on intestinal parasitic infections in school-aged children: A factorial cluster randomized controlled trial", Bhutta ZA, ed. PLoS Medicine, 12(6), 2015.

[13] Chadijah S., Sumolang PPF., Veridiana NN., "The association of knowledge, practice and enviromental sanitation and soil transmitted helminth prevalence in elementary school student in palu municipality", Media Litbangkes 24(1): 50-56, 2014.

[14] Gyorkos TW., Maheu-Giroux M., Blouin B., Casapia M., "Impact of health education on soil-transmitted helminth infections in schoolchildren of the Peruvian Amazon: A cluster-randomized controlled trial", de Silva N, ed. PLoS Neglected Tropical Diseases 7(9), 2013.

[15] Thomas C, et al., "Effectiveness of a rural sanitation programme on diarrhoea, soil-transmitted helminth infection, and child malnutrition in Odisha, India: a cluster-randomised trial", The Lancet Global Health 2(11)645-665, 2014.

[16] Worrell CM., Wiegand RE., Davis SM., Odero KO., Blackstock A., Cuéllar VM., et al., "A cross-sectional study of water, sanitation, and hygiene-related risk factors for soil-transmitted helminth Infection in urban school-and preschool-aged children in Kibera, Nairobi”, PLOS ONE, 11(3), 2016.

[17] Lloyd AE., Honey BL., Barnabas MJ., Condren M., "Treatment options and considerations for intestinal helminthic infections", Journal of Pharmacy Technology 30: 130-139,2014.

[18] Speich B., Ame SM., Ali SM., et al., "Efficacy and safety of nitazoxanide, albendazole, and nitazoxanidealbendazole against Trichuris trichiura Infection: A randomized controlled trial”, Cappello M, ed. PLoS Neglected Tropical Diseases, 6(6):1685, 2012.

[19] Taylor-Robinson DC., Maayan N., Soares-Weiser K., Donegan S., Garner P., "Deworming drugs for soiltransmitted intestinal worms in children: effects on nutritional indicators, haemoglobin and school performance", Cochrane Database Syst Rev 7(7), 2012.

[20] Directorate General of Disease Eradication and Environmental Health. Guidelines for Disease Control, 1 ed. Jakarta: Ministry of Health of the Republic of Indonesia; 2012.

[21] Mascarini-Serra L., "Prevention of soil-transmitted helminth infection", Journal of Global Infectious Diseases, 3(2): 175-182, 2012. 